*Penultimate Draft: Published in A. R. Mele (Ed.), Surrounding self-control (pp. 81-100), Oxford, UK: Oxford University Press.

\title{
Self-Control as Hybrid Skill
}

\author{
Myrto Mylopoulos (Carleton University) \& Elisabeth Pacherie (Institut Jean Nicod)
}

\begin{abstract}
:
One of the main obstacles to the realization of intentions for future actions and to the successful pursuit of long-term goals is lack of self-control. But, what does it mean to engage in self-controlled behaviour? On a motivational construal of self-control, self-control involves resisting our competing temptations, impulses, and urges in order to do what we deem to be best. The conflict we face is between our better judgments or intentions and "hot" motivational forces that drive or compel us to act in opposing ways. In contrast, on an executive construal of self-control, the emphasis is not on overcoming temptation, but on overriding or inhibiting "cold" automatically triggered routines and habits that are at odds with what we intend to do. Our general aim in this chapter is to contribute to the development of an overarching theory of self-control by exploring ways in which these two apparently competing frameworks can be reconciled. We propose that self-control is best understood as a hybrid set of skills. We draw on recent work on expert motor skill to highlight important ways in which experts differ from novices in the capacities they deploy and the ways in which they deploy them. We consider analogies (and disanalogies) between the domain of sports expertise and the domain of self-control. We end by considering how such a hybrid approach can help us reconcile a motivational and an executive approach to self-control.
\end{abstract}

Key words: skill; ego depletion; motivation; sense of control; automaticity

\section{Introduction}

On a common philosophical construal of self-control, self-controlled agents are those capable of acting in accordance with their best judgments or intentions in the face of conflicting forces. In order to further characterize self-control, one must therefore identify these conflicting forces and the kind of control an agent needs in order to successfully resist and overcome them.

On one view, self-control involves struggling against our competing temptations, impulses, and urges to do what we deem to be best. The conflict we face is between our better judgments or intentions and "hot" motivational forces that drive or compel us to act in opposing ways. This view is popular among philosophers. Alfred Mele, for instance, characterizes self-controlled agents as "agents possessed both of significant motivation to conduct themselves as they judge best and of a robust capacity to do what it takes so to conduct themselves in the face of (actual or anticipated) competing motivation" (1995: 5). In addition, the motivational conflicts that are thought to require the exercise of self-control are typically viewed as conflicts between motivational forces competing for the control of intentional action. Self-control and weakness of the will are thus understood as two sides of the same coin. Call this the motivational construal of self-control.

While certain empirical theories of self-control frame the problem of self-control in a similar way (e.g., Baumeister, Vohs, \& Tice 2007), another tradition emphasizes conflicts between so-called executive control and automatic processes (Shiffrin \& Schneider 1977; Shallice \& Burgess 1995; Schneider \& Chein 2003). On this alternative approach, executive control is needed to overcome 
action tendencies induced by automatic processes. The emphasis is not on overcoming temptation, but on overriding or inhibiting "cold" routines and habits that are automatically triggered and at odds with what we intend to do. Call this the executive construal of self-control.

We are thus presented with two construals of self-control that appear to diverge both in what they take the nature of the forces in competition to be and in what they take to be at stake in this competition. On the motivational approach, one's best judgments or intentions are in competition with temptations, feelings, emotions, impulses and similar motivational forces, and their struggle is over the control of intentional action. On the executive approach, executive processes are in competition with automatic processes and their struggle is over the control of action, the possible winners being either intentional actions or actions that, although possibly goal-directed, do not qualify as intentional in a strong sense.

Our general aim in this chapter is to contribute to the development of an overarching theory of self-control and to explore ways in which these two apparently competing frameworks can be reconciled.

In section 2, we consider the various forces that can trump our considered intentions and actions and the various steps in the processes leading from deliberation to action execution at which they can intervene. Given the apparent heterogeneity of the factors that may derail considered action, the question arises whether it makes sense to try and identify a unique resource or a unique profile of cognitive processes on which self-control depends. In section 3, we discuss some extant accounts of self-control that try to meet that challenge and point out some weaknesses of these approaches. In section 4, we delineate our own approach to self-control inspired by recent hybrid theories of skill. Finally, in section 5 we consider the interplay between motivational and executive self-control in light of the proposal we defend.

\section{Self-control and its Enemies}

Motivational approaches to self-control view it as the polar opposite of weakness of the will. The exercise of self-control is needed when contrary forces threaten to derail the action-generation process (or A-process for short) leading from our evaluative judgments, to the formation of appropriate intentions and plans, and finally to their implementation and the execution of corresponding intentional actions. Motivational approaches to self-control identify these contrary forces as temptations, emotions, urges, impulses, strong desires and similar hot motivational forces that intervene at early stages of the A-process.

In addition, a long philosophical tradition has identified weakness of the will with akrasia. An akratic or weak-willed agent is an agent who, despite judging it best to pursue a certain course of action, intentionally pursues another course of action. In contrast, self-controlled agents are agents who act in accordance with their considered judgments. On this understanding of weakness of the will as akrasia and of akratic actions as the opposite of self-controlled actions, the locus of potential conflict is the transition from judging it best to perform a certain action to deciding or forming the intention to perform that action. As we will see, however, the identification of weakness of the will with akrasia has recently been contested. Some authors have proposed instead that weakness of the will is a failure to follow through on one's intentions. On this alternative understanding of weakness of the will, the locus of potential conflict is instead the transition from intention to action.

While the characterisation of self-control as the opposite of akrasia has its roots in Aristotle, it remains alive in contemporary philosophy of action, where it has given rise to important debates about how akrasia is even possible. Following Socrates' lead, some philosophers have argued that akratic actions are, strictly speaking, impossible. The impossibility of akrasia can be argued for in at least two complementary ways. A first line of argument is based on consideration of the function of 
practical reasoning and practical judgment. Thus, on Hare's (1963) view, the function of practical evaluative judgments is to guide conduct and provide an answer to the question 'What shall I do?' that takes the form of a first-person imperative 'Let me do $A$ '. There is thus a special, necessary connection between judging it best to $A$ and forming the intention to $A$. For Hare, an agent who fails to act on her judgment that $\mathrm{A}$ is the best course of action is either insincere -- she does not genuinely believe that that course of action is the best -- or she is unable to so act -- prey to irresistible urges or emotions that compel her to behave contrary to what she judges best. A second, complementary way to argue for the impossibility of akrasia, involves considering the basis of our considered judgments. In arriving at the judgment that $A$ is one's best course of action, one has already taken into account one's desires and motivations. How could one's motivation to $B$ possibly outweigh one's motivation to $A$, given that this motivation to $B$ was already taken into account in judging it best to $A$ ?

In an influential essay, Davidson (1970) offered an analysis of akrasia aimed at vindicating the possibility of akratic actions and pinpointing the specific form of irrationality such actions exhibit. Davidson's argument builds on a distinction between prima facie judgments, all things considered judgments, and all-out judgments. Prima facie judgments are of the form " $A$ is better than $B$ in light of consideration $C$ '. Such judgments need not be relativized to a single consideration, but can in principle take into account multiple considerations. All things considered judgments constitute a subclass of prima facie judgments that assess the relative merits of potential courses of action in light of all the considerations deemed relevant by the agent. Both prima facie and all things considered judgments are conditional or relational judgments. In contrast, all-out judgments are absolute or unconditional judgments of the form " $A$ is better than $B$ " and it is such judgments that bridge practical reasoning and intentional actions. Davidson argues that no all-out judgment logically follows from a prima facie judgment, even an all things considered judgment. Rather this transition is governed by a substantial principle of practical rationality, which he calls "the principle of continence". This principle enjoins agents to perform the action judged best on the basis of all available reasons. Akratic agents are thus not guilty of logical blunder - they do not hold contradictory beliefs - but they are irrational insofar as they fail to abide by the principle of continence.

Some philosophers (Stocker 1979; Mele 1987) have offered a different defense of the possibility of akratic action that involves driving a wedge between evaluation and motivation and arguing that the action one evaluates as best need not be the action one is most motivated to perform. For instance, Mele argues that our judgements of what we should do are based at least in part on our evaluation of the 'objects' of our desires rather than on the motivational force of the desires themselves. Thus, our evaluative judgments should not be seen as mere reflections of the overall balance of our motivational forces. The value we attribute to the objects of our desires may be out of kilter with the motivational force of these desires. It is the misalignment of evaluation and motivation that makes room for akratic action.

An important revisionary strand within motivational approaches to self-control has recently taken hold. Holton (1999, 2003) and McIntyre (2006) have denounced the identification of weakness of the will with akrasia. In their view, weakness of the will is not action contrary to one's considered judgment, but an altogether different phenomenon. Weak-willed agents are agents who fail to follow through on their intentions; their failure is a failure of implementation.

On this revisionary conception of weakness of the will, the locus where the exercise of selfcontrol is needed to resist conflicting forces is not the transition from judgment to intention but rather the transition from intention to action. In addition, whereas weakness of the will understood as akrasia is a synchronic phenomenon involving a conflict between contemporaneous evaluative and motivational states, weakness of the will understood as irresoluteness is a diachronic 
phenomenon, a conflict between the intention formed at a certain point in time to act in a certain way at some later point in time and what one actually does (or fails to do) at that later point.

Not all instances of failing to act on one's intentions constitute weakness of the will. Circumstances may make it impossible to carry out one's intentions or make it reasonable to revise them. Rather, agents exhibit weakness of the will when they are too ready to reconsider their intentions. Appealing to Bratman's planning theory of agency (1987), Holton argues that the point of forming future-directed intentions and plans is to extend our agency over time, allowing us to coordinate our present self with our future selves and thus to promote overall desire satisfaction. Giving up too easily on our intentions is thus irrational in that it defeats the purpose of planning agency. To further distinguish weakness of the will from more benign changes of mind and more precisely locate its irrationality, Holton and McIntyre introduce a further specification. They propose that weakness of will consists in failing to act on a special sort of intention, a resolution, which can be defined as "an intention to act despite anticipated contrary inclination that is formed because the agent anticipates that she will feel the pull of contrary inclinations when the time to act comes" (McIntryre, 2006: 295). Thus, weakness of the will appears especially criticizable because it involves giving in to a temptation the intention was designed to counteract. As McIntyre also puts it, the failure of practical rationality here at stake is a failure of self-management.

It is unclear, however, whether we should draw a sharp demarcation line between akrasia and irresoluteness and insist that weakness of the will is to be identified with one or the other, but not both, rather than considered as a genus of which both are species and that may contain further species. Thus, Stroud (2010) argues that procrastination cuts across the demarcation line between akrasia and irresoluteness. Like irresoluteness, procrastination has an essentially diachronic character and involves a failure to implement our plans. At the same time, procrastination also centrally involves a conflict between the agent's intentional behaviour and some of her evaluative attitudes. The procrastinator fails to act at $t$, despite judging it best to act at $t$.

In addition, there are also practical failures involved in procrastination that are neither decision failures, as in akrasia, nor plan implementation failures, as in irresolution, but rather failures in plan drafting and plan adoption. In particular, in procrastination, "we can plan badly when we adopt only a vague or undemanding plan when a stronger, more specific plan is required" (Stroud, 2010: 64). In that case, the procrastinator may be guilty of failing to anticipate potential future contrary inclinations or of failing to form appropriate resolutions.

Thus, as Stroud concludes, both the classical understanding of weakness of the will as akrasia and its revisionist understanding as irresoluteness appear to exclude some instances of procrastination from counting as weak-willed. She proposes that what is common to the full range of cases of procrastination is that "we are doing a bad job at something essential to temporally extended agency: placing activity in time." (2010: 66).

This suggests that akrasia, irresoluteness and procrastination may all count as instances of weakness of will. On this broader understanding of weakness of will, what all instances of weakness of will would still have in common is their being failures of motivational self-management and as such failures of practical rationality. Such an understanding of weakness of the will sits well with a motivational construal of self-control as a capacity for motivational self-management. Adopting it would allow us to maintain that self-control and weakness of the will are two sides of the same coin.

However, there are reasons to think that self-control is needed not just to anticipate and counteract contrary motivational forces but also to prevent other kinds of practical failings. Holton and McIntyre appeal to the centrality of planning to human agency to argue that irresoluteness, resulting in failure to implement one's plans, is a rational failing. But, as Stroud argues, there are certainly other flaws in our planning activity that should count as practical failings. Irresoluteness or indeed procrastination are not the only criticizable ways in which we can fail to implement our plans. 
We can also fail to act on our intentions, because they slipped our mind. For instance, one may completely forget about the dinner party one had planned to attend. In some instances, forgetting about the dinner can be easily excused and not constitute a rational failing - e.g., your house just burned down and all your attention is concentrated on that disaster. But if you are prone to forgetfulness and know about it, you incur blame for not taking steps (tying a knot in your handkerchief or, if you are more technologically savvy, setting an alarm on your smartphone) to prevent such lapses of memory. Similarly, if you customarily find yourself wondering what you meant to buy when in a grocery store, you may be blamed for not making a shopping list beforehand. Note that while some instances of forgetting about our intentions may be motivated (e.g., conveniently forgetting a dentist's appointment), this need not always be the case. You were perhaps looking forward to the dinner party and you probably hate having to go back to the grocery store because you forgot some essential item.

In addition, as advocates of an executive construal of self-control insist, failure to implement a plan or carry it through is often due to the hijacking of behaviour by automatically triggered routines or habits. Joseph may leave his office intent on stopping at the dry cleaner before going home and realize upon arriving at his doorstep that he completely forgot about the dry cleaner. What happened is that he let his behaviour be steered by automatic processes triggered by familiar landmarks. Similarly, the literature on action errors (e.g. Reason, 1990) suggests that action slips and lapses often result from the intrusion of strong habits and well-established action sequences. Thus, it seems that just as self-control can involve anticipating and counteracting contrary inclinations, it can involve anticipating the intrusion of unwanted automatic routines and preventing automatic processes from running the show unchecked.

It appears then that what we called the A-process can be ambushed at all its stages, from initial decision and intention formation, through plan drafting and adoption, all the way to plan implementation and action execution. In addition, the ambushers may be 'hot' motivational forces but also 'cold' automatic routines. To the extent that we can anticipate these ambushes, failures to do so and to take steps to prevent their success count as practical rationality failings.

This calls for a broader conceptualization of self-control that goes beyond motivational selfmanagement to include other forms of practical self-management. A further reason for adopting this broader characterization of self-control is that the behaviours we seek to curb by exercising selfcontrol often have both a motivational and an automatic or habitual dimension. For instance smoking can be described as driven by a craving for nicotine but also, at the same time, as habitual behaviour triggered by stimuli in the environment. Finally, 'forewarned is forearmed' is an adage that applies equally to exercises of self-control aimed at resisting temptations and at resisting interference from automatic routines. In both cases, anticipation and, more generally, self-knowledge play an important role in self-control.

\section{General Models of Self-Control}

Given the heterogeneity of the factors that may induce a loss of self-control, we must adopt a more general model of what self-control and its psychological mechanisms are. We now turn to considering two such models, before advancing our own model in section 4.

\subsection{The Strength Model of Self-Control}

On one influential psychological model, known as the Strength Model of Self-Control (Baumeister, Vohs, \& Tice, 2007), self-control depends on the limited energy resource of 'willpower'. The core idea behind this model is that self-control is like a muscle: when it is exercised for a prolonged period of time it will become fatigued and performance will drop until the energy on which it draws is 
restored. A main prediction of this model is that the more tasks requiring self-control one engages in within a certain period, the less one will be able to exercise self-control, since one's general resource will be gradually depleted. This predicted effect has come to be known as "ego depletion".

Studies that are appealed to in support of the Strength Model and the depletion effect typically follow roughly the same design, known as the dual-task paradigm (Baumeister et al., 1998). Participants assigned to the "ego depletion" group are given a self-control task, the successful completion of which requires that they exercise a high degree of self-control. For instance, they may be seated in front of a bowl of radishes and a plate of cookies and told to eat the radishes and avoid the cookies. Next, they are given a secondary self-control task to complete. For instance, they might be given a puzzle that is in fact unsolvable. In the control group, participants are also given two consecutive tasks to complete, but only the secondary tasks requires self-control. The finding reported across numerous studies, and predicted by the Strength Model, is that those in the ego depletion group perform more poorly on the secondary control task than those in the control group (see Hagger et al. 2010 for a meta-analysis and review).

Importantly, the kinds of tasks used in these experiments are not restricted to controlling behaviour in light of competing motivational forces. They can also involve suppressing habitual responses, as in one study, where participants were instructed to suppress their emotions while watching an emotionally charged video (Muraven et al., 1998). So on the Strength Model, selfcontrol is a general resource that can be used to combat a range of interfering psychological factors, not simply restricted to hot motivational forces like temptations and urges. It also gives us some limited predictions. Self-control is likely to be higher earlier in the day, when our willpower reserves are at their highest. Researchers have also suggested a surprising effect linking glucose levels to one's capacity to exercise self-control (e.g., Gailliot \& Baumeister, 2007; but see Kurzban, 2010).

Still, the Strength Model faces some important challenges. Perhaps most pressing is the troubling recent publication of a meta-analysis, correcting for some factors in a previous metaanalysis by Hagger et al. (2010), that found no effect of ego depletion (Carter et al., 2015). In light of this, it seems safest to hold that the jury is still out as to whether the basic effect that is the driving engine behind the Strength Model even exists.

Supposing that the effect does exist, however, the theoretical model on offer still leaves us without a clear explanation of the psychological mechanisms underlying self-control. What specific self-control functions does this resource support, and how exactly does it do so? The model also leaves unaccounted for cases of persistent breakdowns in self-control that do not seem to be related in any clear way to ego depletion. Consider the perennially relapsing "ex"-smoker. It is unlikely that every token instance of giving into an urge to smoke, despite a prior resolution not to, can be traced back to a depleted ego. Consider also someone who breaks a resolution first thing in the morning, before they have had to exercise any self-control. Perhaps they have chocolate cake for breakfast instead of the healthy fruit they had told themselves they were going to have the night before. The Strength Model does not give us any way to diagnose what is happening in such cases. A more detailed account of the psychology of self-control would serve us well here.

\subsection{Levy's Dual-Systems Model of Self-Control}

Recently, Neil Levy (2011) has proposed a model of self-control that can be understood as an attempt to cash out the Strength Model's metaphor of "willpower" as a limited energy resource. Levy notes that ego depletion can occur across a range of cases that are not restricted to the domain

of self-control. For instance, he points out that engaging in the Stroop task can lead to ego depletion for subsequent tasks (Webb and Sheeran 2003), but there is no temptation being battled, or resolution being revised in this case. On these grounds, Levy argues that weakness of the will, i.e., a 
lapse in self-control, is not, in fact, a psychological kind: "The behaviour we call weakness of the will exists, but the concept is useful neither for the explanatory purposes of psychology, nor for the practical purposes of increasing our ability to maintain self-control." (148).

Instead, Levy views weakness of the will, and the self-control needed to combat it, as instances of a more general phenomenon tied to a dual-process model of cognition (Tversky \& Kahneman, 1974; Evans \& Stanovich, 2013). On such models, there are two types of cognitive processes, those lumped under 'system 1' (or 'type 1') processes and those lumped under 'system 2' (or 'type 2') processes. System 1 processes tend to be fast, implicit, automatic processes that are undemanding of cognitive resources. Parsing speech in one's native tongue or recognizing a string of symbols as numbers are examples of system 1 processes. By contrast, system 2 processes tend to be slow, effortful, rule-governed, typically conscious, and demanding of cognitive resources. Engaging with a difficult math problem, or reasoning about when you must leave to arrive at an appointment on time are examples of system 2 processes. According to Levy, "self-control is a system 2 process, and its loss switches us to system 1" (145). In other words, when ego depletion occurs, we are forced to rely on our relatively "brutish" system 1 processes, and the self-control processes supported by system 2 cannot be as easily accessed.

Levy's model makes some progress over the basic Strength Model of self-control. For one, it gives us a more specific way of understanding are the psychological mechanisms underlying selfcontrol: it is, specifically, that set of processes governed by system 2 . So whatever properties we discover those processes to have more generally, can applied to our understanding of self-control in particular. This allows for relatively more subtle predictions than does the Strength Model.

Still, Levy's model faces a number of shortcomings as well. First, in some cases weak-willed behaviour is a triumph of system 2 processing. The carefully planned acquisition of a drug and thoughtfully orchestrated administration of it in terms of timing, location, amount, and so on, might be a case of acting against one's better judgement or irresoluteness in sticking to one's intentions, while at the same time drawing heavily on system 2 processes (cf. Kennett, 2013; Mele, 1990 on errant self-control).

Second, and on the flip side, Levy's account does not do justice to the role that system 1 processes may play in self-controlled behaviour. As pointed out by Kennett (2013), "since controlled processing is a limited resource, the self-controlled person is, plausibly [...], the person who doesn't need to draw on this resource too often in order to act as she desires, values or intends. She has a well-schooled automatic system that preserves self-control even when attentional resources are depleted" (152). Another way that this point can be put is that the self-controlled agent is an agent with good habits and routines, where these can be viewed as the product of system 1 processes. As William James (1890) reminds us, "[t] he great thing, then, in all education, is to make our nervous system our ally rather than our enemy... For this we must make automatic and habitual, as early as possible, as many useful actions as we can, and guard against the growing into ways that are likely to be disadvantageous to us, as we should guard against the plague" (vol 1: 122). While Levy's view seems to assume that system 1 processes are often or typically responsible for breakdowns in self-control, in many cases it seems as though we must rely on system 1 in order to maintain it.

A third problem for Levy's view, as Holton points out, is that being skilled at system 2 processing (e.g., being strong at formal logic) does not always correlate with being skilled at selfcontrol $^{1}$. But if self-control is just the deployment of system 2 processes, then this dissociation should not exist.

\footnotetext{
${ }^{1}$ Levy (2011:150) indicates that this objection was raised by Holton in a personal communication.
} 
In response, Levy argues that people who are successful at resisting temptation do not do so because they have "greater reserves" of system 2 resources, but rather because they are better at avoiding the overuse of these resources. He points out that the children that did best in Walter Mischel's classic marshmallow task were the ones that were able to distract themselves (see Mischel et al., 1989). Those who did the worst were focused on the marshmallows that they were trying not to eat. Levy argues that these self-distraction techniques allowed the successful children to avoid taxing their system 2 resources, and it is this that explains their greater exercise of self-control, not that they had more of such resources to begin with. He writes, in accordance with Mischel, that "the ability to delay gratification depends not on strength of will, or the state of system 2 resources, but on the ability to deploy a skill' (150) (emphasis ours).

We wholeheartedly agree. ${ }^{2}$ As we will explain in the next section, our view, broadly, is that self-control is a form of hybrid skill. Indeed, once one recognizes that self-control involves not just the bare strength of system 2 processes, but the deployment of a set of skills that results in the effective use of both system 1 and system 2 processes, a model like Levy's on which self-control is a system 2 process and breakdowns in self-control reflect system 1 processing becomes too crude. What we need instead is a better understanding of how it is that system 1 and system 2 processes coordinate and interact in order to produce self-controlled behaviour across a range of circumstances, and how this coordination gets honed up over time with deliberate effort and attention. This, we maintain, requires that we understand self-control as a type of skill.

Thus, we propose to construe self-control as a hybrid skill learned through practice and involving rich and fine-tuned interactions between processes typical of system 1 processing, i.e., automatized motor routines and procedures, and those typical of system 2 processing, i.e., the deployment of rules and other propositional states, at stages ranging from deliberation and intention formation to action execution. We draw on recent work on expert motor action to highlight important ways in which experts differ from novices in the capacities they deploy and the ways in which they deploy them. We then apply lessons from the domain of motor expertise to the domain of self-control. We turn now to these tasks.

\section{Section 4: Self-Control as Hybrid Skill}

We start by distinguishing among three approaches to understanding skill. On a strongly intellectualist view, skill primarily involves the guidance of behaviour by way of strategic intentions or the application of rules or knowledge in propositional format representing what to do in a given situation. What the skilled agent knows is that these rules apply in certain contexts and situations within which they find themselves, and this allows them to form customized, strategic intentions to guide their behaviour in the situation at hand. By contrast, on a strongly anti-intellectualist approach, skill is instead best construed as the abandonment of rules and propositional thought or intention. The skilled agent does not think, she simply does. Skilled behaviour is thus a function of the automatization and fine-tuning of sensorimotor procedures that allow the agent to interact flexibly with her environment across a range of circumstances.

One might be excused for viewing the long-standing debate on the nature of skill as an endless tug-of-war between these competing accounts. Recently, however, a family of views has emerged that takes a promising middle road. Such views allow that skill is constituted both by

\footnotetext{
${ }^{2}$ Others before us have also broadly agreed. For instance, Mele (2011) writes, "Our powers of self-control include a variety of skills - and considerable savvy about which skills to use in particular situations (469).
} 
strategic intentions and the application of propositional rules or knowledge, and fine-tuned, automatized sensorimotor routines. The key to understanding skill, on such views, is to understand how it is that these different types of states and processes coordinate and interact, and how the division of labour among them is distributed. We call these hybrid views of skill. As mentioned, we propose to view self-control as a type of hybrid skill.

On our view, at the heart of any skill are three different types of control: automatic motor control, situational control, and strategic control. We will illustrate each of these in turn, starting with a skill domain that is familiar - that of expert tennis — and then extending this account to our target domain of self-control.

Consider the professional tennis great Rafael Nadal. Nicknamed "the King of Clay", he is thought by many to be the best clay-court tennis player of all time. With sixteen Grand-Slam singles titles, no one would doubt that his level of skill at tennis is of the highest order. What does it take for someone to become as skilled at tennis as Nadal?

We may start by noting that, of course, any expert athlete might be possessed of some "natural gifts", that is, innate aptitudes and traits that may offer them an advantage within some skill domain. Someone who is born tall may thereby have an advantage in basketball over someone who is of average height. Indeed, there is some folk attraction to a "natural gifts" conception of skill. For instance, the swimmer Michael Phelps, who is the most decorated Olympian of all-time, is often said to have double the lung capacity of the average human. But this widely spread assertion has not actually been borne out by any empirical evidence. On our view, "natural gifts" are neither necessary nor sufficient for expertise. One can be born with height and yet be hopeless on the basketball court. Conversely, one might overcome one's height disadvantage in ways that allow them to become an elite player.

Expert skill does not lie in innate greatness, but in the development and fine-tuning of distinct types of control through deliberate practice over time. To begin, one must acquire a high degree of automatized motor control. In tennis, this primarily involves technical motor skills relating to the serve, and to different types of stroke (e.g., forehand, backhand, volley, lobbing). Mastering these skills involves a mastery of different calculations relating to racquet grips; how forcefully, high, or far to hit the ball; how precisely to position the racket-head, and so on. Once the complex mechanics of these motor skills are mastered, the tennis player is able to reliably and effortlessly perform them across a range of circumstances, often maximizing dimensions of these skills to astonishingly high degrees.

But skill at tennis goes well beyond this technical mastery. It also involves what we call situational control. This is the occurrent perceptual awareness one has of relevant features of the environment as one is engaged in skilled action. This involves the comprehension of their significance to the present context, and the ability to project from current events and dynamics to anticipated events in the near future (Endsley, 1995, 2006). Unsurprisingly, then, situational control relies heavily on the proper deployment of attention to the situation at hand. Indeed, it is known that experts differ from non-experts in how efficiently they allocate their attention, and the amount of information they can extract from their environment on the basis of such allocation (Mann et al., 2007). They are significantly better than non-experts, at "knowing where to look" in order to extract the right information at the right time so that they can both program their next move and predict what will happen next. On this latter front, studies suggest that expert tennis players are able to use earlier perceptual cues than non-experts in order to anticipate the upcoming movements of their opponents (Jones and Miles 1978). Among other advantages, this more efficient allocation of attentional resources frees up more time for them to use for rapid decision-making and technical footwork. 
Finally, skill in sport also involves a high degree of strategic control. Such control is primarily driven by domain-specific knowledge and deliberation about how to play and what to do in specific contexts. It is acquired over years of extensive practice and experience within a skill domain, and is often helped along by explicit guidance from a coach or mentor. To illustrate, a skilled tennis player's decision about where to hit the ball next is not just based on their awareness of their position and their anticipated awareness of their opponent's position, but also on knowledge of their own as well as their opponent's strengths and weaknesses, and their knowledge of the general state of the game. For example, Nadal does not play Roger Federer, who is known to be weaker on his backhand, in the same way that he plays Andy Murray, who is known to be weaker on his forehand. Similarly, he prefers to engage in long exchanges when he is playing on a clay court, and shorter exchanges on a harder surface. This general knowledge allows for the high degree of flexibility in strategy and approach that is a hallmark of expert skill.

Let us now apply this general framework for understanding skill to the domain of selfcontrol. Like skill in sport, we take skill in self-control to involve the acquisition and development of strategic control, situational control, and automatic motor control. We add that there is also an element of normative control that one must acquire. This involves the capacity to govern oneself in accordance with one's broader values, commitments, and projects. Though this dimension of selfcontrol is significant, we will not say anything further about it here. We will focus instead on more local levels of control that the self-controlled agent must possess.

Perhaps most important for self-control is strategic control. In this context, this amounts to general knowledge of one's own strengths and weaknesses, and on that basis the ability to anticipate a potential loss of control given the upcoming situation of action. The knowledge involved in strategic control involves knowledge of one's triggers, temptations, aversions, phobias, and typical patterns of motivational states. Someone who knows that they tend to crave cigarettes after dinner will use this knowledge in order to plan to modify their behaviour within that context, even if they have no such craving at the present moment. The two background conditions for strategic control are the ability to acquire self-knowledge and to think about the future. This means that this aspect of self-control will not be available to everyone. As McIntyre (2006) notes, "[y]oung children certainly [...] lack the ability to predict their future motivational states and to make plans that explicitly take them into account by forming resolutions" (297). Thus, we should not expect them to engage in the strategic aspect of self-control.

A prominent example of applying this general knowledge in the service of self-control is the formation of so-called "implementation intentions" (Aarts, Djiksterhuis, \& Midden, 1999; Gollwitzer, 1999; Webb and Sheeran, 2007). Implementation intentions are intentions the content of which takes the form $<$ If situation $x$ arises at time $y$ in location $z$, I will do A $>$. The role of an implementation intention is to link anticipated situational cues with a specific action outcome. There is by now extensive empirical evidence that forming such intentions increases the likelihood of goal attainment (for a review, see Gollwitzer \& Sheeran 2006). For example, one is more likely to take one's vitamins if one forms the implementation intention to take the vitamins when one sees the bottle on one's bedside table upon waking up at 7am, than if one forms the general intention to take one's vitamins every day (Sheeran \& Orbell 1999). Similarly, one can form an implementation intention to say 'no' in the event that one is offered dessert at the dinner party one will attend later this evening. Anticipating situational cues that are likely to lead one to act contrary to some resolution, intention, or better judgement, and forming corresponding implementation intentions amounts to a type of strategic control that one can use to become better at self-control.

Next, skill at self-control requires the exercise of situational control, which here involves awareness of perceptual features of one's environment as well as one's internal states in the situation of action and the appropriate deployment of attention. Here we see an interesting disanalogy 
between situational control as it is often exercised in sport skill and situational control as it is often exercised in self-control. Whereas in sport, it frequently helps to deploy attention to important features of one's environment (e.g., the opponent's foot position), in the case of self-control, it often helps to move one's attention away from some feature of the environment that is serving as a temptation. Of course, in order to move one's attention away and appropriately distract oneself from the salient feature, one must be aware that it is there in the first place. Thus, some degree of attention to it is necessary. But after this initial stage of picking up the relevant information, the corresponding deployment of attention should involve focusing on other things.

There are at least two strategies one might use for this. First, one may engage in intentional self-distraction, as we mentioned previously in the context of Mischel's marshmallow test. There is also some suggestion in the empirical literature that mindfulness meditation, which is used to train attentional awareness, can help to combat self-control failures by promoting self-distraction (Friese et al. 2012). Here it is important to note that mindfulness meditation typically works by focusing one's attention on some aspect of one's experience, e.g., one's breathing or bodily sensations. And what this does is, in effect, occupy attention and prevent it from being directed towards things that one is attempting to avoid focusing on, e.g., the plate of cookies in front of you.

Another strategy for implementing situational control relates to combatting effects such as time discounting. This refers to viewing smaller present rewards as more enticing than larger distant rewards. In mental time travel (MTT), visual and auditory imagery combine with activation of emotional circuitry to create "ersatz" experience, triggering emotional rewards that reflect the emotional impact of the hypothetical situation. MT'T may thus help us counter a natural tendency towards time discounting and impulsive, opportunistic behaviour, and be essential to motivation regulation (Boyer, 2008).

Finally, we turn to automatic motor control. As might be expected, this has a more minor role to play when it comes to self-control than it does in other skill domains. Still, reinforcing and automatizing desired stimulus-response pairings, as automatic motor control requires, is an important component of self-control. This can be viewed as akin to good habit formation, which as we mentioned earlier, is of great importance for the self-controlled agent. Indeed, there is evidence that approach/avoidance bias modification can help to improve self-control in certain domains. In one study, Wiers et al. (2011) had patients assigned to one of two experimental conditions, in which they were implicitly or explicitly trained to make avoidance movements (pushing a joystick) in response to alcohol pictures. Alternatively, they were assigned to one of two control conditions, in which they received no training or sham training. In the experimental conditions only, patients' approach bias changed into an avoidance bias for alcohol. The results were that patients in the experimental conditions showed better treatment outcomes a year later than those in the control conditions. The authors conclude that " $[t]$ hese findings indicate that a short intervention can change alcoholics' automatic approach bias for alcohol and may improve treatment outcome" (490).

To recap, we have argued that if we restrict the scope of self-control to motivational conflicts, then we fail to account for failures of practical rationality that involve the hijacking of behaviour by automatic processes. At the same time, it would be wrong to simply construe success at self-control as a function of executive processes, and failure of self-control as a matter of automatic processes. Instead, what is needed is an account of self-control that explains how executive and automatic control processes can coordinate and interact. The account of self-control we have just proposed treats it as a form of hybrid skill developed through practice, the acquisition of self-knowledge, and the honing and fine-tuning of different types of interactive control strategies. Such a conceptualization of self-control has the potential to provide a unifying framework by recognizing the various forms taken by (ordinary) failures of self-control and the many ways in 
which people can promote self-control. It makes sense of the idea that self-control can be trained and can develop over time.

\section{Conclusion: Executive and motivational control revisited}

We now conclude with some suggestions as to how the framework we have presented relates to the motivational construal of control with which we began our discussion.

As we have stressed, weak-willed behaviour is often both behaviour driven by hot motivational forces and behaviour that unfolds automatically. Smoking, for instance, is both a craving and a habit. A hallmark of automatic or habitual behaviour is its effortlessness. Weak-willed actions may thus often be not just tempting options but also options that are easy to implement.

The expectancy theory of motivation (ETM for short) proposes that motivation is a product of how much one wants something and of one's expectation and level of confidence that one is capable of achieving it (Vroom 1964; Eccles \& Wigfield 2002). More precisely, ETM takes motivation to be a function of three main factors: the desirability of the outcome for the agent (valence), the subjective probability that the proposed action will yield that outcome (instrumentality) and the confidence one has that one can perform the action (expectancy). While ETM was initially developed in the context of work and organizational psychology, it has been applied in a number of other areas, including education and addiction. We propose that it offers a useful framework for understanding the interplay between the motivational and executive dimensions of failures of selfcontrol, but also, conversely, for understanding how self-control can develop and become easier over time.

Smoking ranks high on the three components of motivation distinguished by ETM. Its outcome, the satisfaction of a craving for nicotine, has high positive valence for the agent, the action is easy to implement and it is sure to yield the desired result. Other instances of weak-willed behaviour may not rank so high on desirability or valence, but still be high on the other components of motivation. Take Lucy, sitting on her couch watching TV instead of at her desk working on her overdue paper. The TV program she's watching need not be the latest episode of her favorite series; it can be your typically moronic and boring TV afternoon talk show. What keeps her away from her desk may not be so much the desirability of watching that program as the effortlessness of remaining in her couch doing nothing compared to the effort involved in writing her essay (and her lack of confidence that her best effort will result in a good grade). ETM can thus explain why one may think it best to pursue a course of action and yet be more motivated to pursue another: the considered action might rank higher on valence or desirability than the weak-willed action, yet rank lower on expectancy and instrumentality.

The flip side of this story is that developing self-control skills may make considered actions easier to implement, thus raising our levels of expectancy and instrumentality and our motivation to act as we consider best. A virtuous circle of self-control could thus be initiated and sustained.

But how exactly are expectancy levels raised and motivation strengthened? It is useful to distinguish two routes through which this may be achieved: the belief route and the feeling route. An agent's expectancy - her degree of confidence that she will be able to act in a self-controlled manner - depends in part on her explicit beliefs that she has the requisite skills and that the deployment of these skills will yield the desired results. Previous episodes of success or failure at self-control can reinforce or weaken these beliefs. But there is also evidence that exposure to theories about self-control can modulate self-control. For instance, studies have shown that when people believe that willpower is an abundant (rather than highly limited) resource they exhibit better self-control after demanding tasks (Job et al. 2010, 2015) or that weakening belief in free will reduces self-control (Rigoni et al. 2012). 
An agent's expectancy, may also depend on subjective feelings of control. The sense of agency refers to the subjective feeling of controlling one's actions and, through them, events in the outside world. Early research on the sense of agency, emphasized the importance of predictionoutcome matching: the better the outcome of an action fits our predictions, the stronger our sense of agency (Moore \& Haggard 2008; Sato \& Yasuda, 2005; Wegner \& Wheatley, 1999). More recent work, however, supports the possibility that the sense of agency is partly generated prospectively rather than purely retrospectively. It suggests that selecting between alternative possible actions might itself generate a sense of agency (Wenke, Fleming, \& Haggard, 2010; Chambon \& Haggard 2012; Chambon, Sidarus \& Haggard, 2014). A strong sense of agency may be associated with fluent, uncontested action selection, while conflict between alternative possible actions may reduce the feeling of control. While, for methodological reasons, empirical research has largely confined itself to the investigation of our sense of control of particular action tokens, it is plausible that our occurrent sense of control, especially if it has a prospective dimension, may also foster over time a dispositional sense of control for actions of a given kind, something akin to an intuition that we are able to perform such actions.

In addition, we should also expect a positive correlation between fluency and automaticity. Automatic processes are typically effortless and fluent. As we have seen in section 4, efficient selfcontrol often strategically calls on automatic processes. Automatizing self-control and thereby increasing its fluency could thus contribute to raising our expectancy that our attempts at selfcontrol will be successful and with it our motivation to engage in such attempts. The existence of this second route to expectancy enhancement would further suggest that, apart from the motivational force that is commonly thought to attach to propositional attitude states, there is sense to be made of motivational strength as attaching to automatic processes.

\section{References}

Aarts H., Dijksterhuis A.P., \& Midden C. (1999). To plan or not to plan? Goal achievement or interrupting the performance of mundane behaviors. European Journal of Social Psychology, 29(8), 971-979.

Baumeister, R. (2012). Self-control: The moral muscle. The Psychologist, 25, 112-115.

Baumeister, R., Bratslavsky, E., Muraven, M., \& Tice, D.M. (1998). Ego depletion: Is the active self a limited resource? Journal of Personality and Social Psychology, 74(5), 1252-1265.

Baumeister, R. F., Vohs, K. D., \& Tice, D. M. (2007). The strength model of self-control. Current Directions in Psychological Science, 16(6), 351-355.

Boyer, P. (2008). Evolutionary economics of mental time travel? Trends in Cognitive Science, 12(6), 219-224.

Carter, E.C., Kofler, L.M., Forster, D.E., McCullough, M.E. (2014). A series of meta-analytic tests of the depletion effect: Self-control does not seem to rely on a limited resource. Journal of Experimental Psychology General, 144(4), 796-815.

Chambon, V., \& Haggard, P. (2012). Sense of control depends on fluency of action selection, not motor performance. Cognition, 125(3), 441-451.

Chambon, V., Sidarus, N., \& Haggard, P. (2014). From action intentions to action effects: how does the sense of agency come about? Frontiers in human neuroscience, 8.

Davidson, D. (1970). “How Is Weakness of the Will Possible?”, reprinted in Davidson 1980, Essays on Actions and Events, Oxford: Clarendon Press, pp. 21-42.

Eccles, J. S., \& Wigfield, A. (2002). Motivational beliefs, values, and goals. Annual Review of Psychology, 53, 109-132. 
Endsley, M.R. (1995) Toward a theory of situation awareness in dynamic systems. Human Factors, 37, 32-64.

Endsley, M. R. (2006) Expertise and situation awareness. In K. A. Ericsson, N. Charness, P. J. Feltovich \& R.R. Hoffman (eds). The Cambridge Handbook of Expertise and Expert Performance. Cambridge: Cambridge University Press.

Evans J.S.B.T. \& Stanovich K.E. (2013). Dual-process theories of higher cognition advancing the debate. Perspectives in Psychological Science, 8, 223-41.

Friese, M., Messner, C., Schaffner, Y. (2012). Mindfulness meditation counteracts self-control depletion. Consciousness and Cognition, 21(2), 1016-1022.

Gailliot, M. T., \& Baumeister, R. F. (2007). The physiology of willpower: Linking blood glucose to self-control. Personality and social psychology review, 11(4), 303-327.

Gollwitzer, P.M. (1999). Implementation intentions: strong effects of simple plans. American Psychologist, 54, 493-503.

Gollwitzer, P.M. \& Sheeran, P. (2006). Implementation intentions and goal achievement: a metaanalysis of effects and processes. Advances in Experimental Social Psychology, 38, 69-119.

Hagger, M. S., Wood, C., Stiff, C., \& Chatzisarantis, N. L. (2010). Ego depletion and the strength model of self-control: A meta-analysis. Psychological Bulletin, 136, 495-525.

Hare, R. M. (1963). Freedom and Reason, Oxford: Clarendon Press.

Holton, R. (1999). Intention and Weakness of Will, Journal of Philosophy, 96: 241-262.

Holton, R. (2003). "How is Strength of Will Possible?”, in Stroud and Tappolet (eds.) Weakness of Will and Practical Irrationality, Oxford: Clarendon Press., pp. 39-67.

Job, V., Dweck, C. S., \& Walton, G. M. (2010). Ego depletion-Is it all in your head? Implicit theories about willpower affect self-regulation. Psychological science, 21(11), 1686- 1693.

Job, V., Walton, G. M., Bernecker, K., \& Dweck, C. S. (2015). Implicit theories about willpower predict self-regulation and grades in everyday life. Journal of Personality and Social Psychology, 108(4), 637-647.

Jones, C.M., \& Miles, T.R.. (1978). Use of advance cues in predicting the flight of a lawn tennis ball. Journal of Human Movement Studies, 4, 231- 5.

Kennett, J. (2013). Just say no? Addiction and the elements of self-control. In N. Levy (Ed.), Addiction and Self-Control: Perspectives from Philosophy, Psychology, and Neuroscience, New York:

Oxford University Press, pp.144-163.

Kurzban, R. (2010). Does the brain consume additional glucose during self-control tasks?. Evolutionary Psychology, 8(2): 244-259.

Levy, N. (2011). Resisting 'Weakness of the Will'. Philosopby and Phenomenological Research, $\quad$ 82(11), 134-155.

Mann, D., Williams, A.M., Ward, P., \& Janelle, C.M.. (2007). Perceptual-cognitive expertise in sport: A meta-analysis. Journal of Sport \& Exercise Psychology, 29, 457-478.

McIntyre, A. (2006). What is wrong with weakness of will? Journal of Philosophy, 103, 284- 311.

Mele, A. R. (1990). Errant self-control and the self-controlled person. Pacific Philosophical Quarterly, 71, 47-59.

Mele, A. R. (1995). Autonomous Agents: From Self-Control to Autonomy. Oxford, UK: Oxford University Press.

Mele, A., (1987). Irrationality, New York: Oxford University Press.

Mischel, W., Shoda, Y., \& Rodriguez, M. L. (1989). Delay of Gratification in Children. Science, 244(4907), 933-938.

Moore, J., \& Haggard, P. (2008). Awareness of action: Inference and prediction. Consciousness and cognition, 17(1), 136-144. 
Muraven, M., Tice, D. M., \& Baumeister, R. F. (1998). Self-control as a limited resource:

Regulatory depletion patterns. Journal of Personality and Social Psychology, 74, 774- 789.

Reason, J. (1990). Human Error. Cambridge, MA: Cambridge University Press.

Rigoni, D., Kühn, S., Gaudino, G., Sartori, G., \& Brass, M. (2012). Reducing self-control by weakening belief in free will. Consciousness and cognition, 21(3), 1482-1490.

Sato, A., \& Yasuda, A. (2005). Illusion of sense of self-agency: discrepancy between the predicted and actual sensory consequences of actions modulates the sense of self- agency,

but not the sense of self-ownership. Cognition, 94(3), 241-255.

Schneider, W. \& Chein, J.M. (2003). Controlled and automatic processing: Behaviour, theory, and biological mechanisms. Cognitive Science, 27, 525-559.

Shallice, T., \& Burgess, P. (1996). The domain of supervisory processes and temporal organization of behaviour. Philosophical Transactions of the Royal Society of London. Series

B: Biological Sciences, 351(1346), 1405-1411.

Shiffrin, R. M., \& Schneider, W. (1977). Controlled and automatic human information processing. II. Perceptual learning, automatic attending and a general theory. Psychological

Review, 84(2), 127-190.

Stocker, M. (1979). Desiring the Bad: An Essay in Moral Psychology. Journal of Philosophy, 76, 738-753.

Stroud, S. (2010). Is Procrastination Weakness of the Will? In Andreou and White (eds.) The Thief of

Time, Oxford: Oxford University Press, p. 51-67.

Tversky A. \& Kahneman D. (1974). Judgment under uncertainty: Heuristics and biases. Science, 185: 1124-31.

Vroom, V.H. (1964). Work and Motivation. New York, NY: Wiley.

Wegner, D. M., \& Wheatley, T. (1999). Apparent mental causation: Sources of the experience of will. American Psychologist, 54(7), 480-492.

Wiers, R.W., Eberl, C., Rinck, M., Becker, E.S., Lindenmeyer, J. (2011). Retraining automatic action tendencies changes alcoholic patients' approach bias for alcohol and improves treatment outcome. Psychological Science, 22(4), 490 - 497

Wenke, D., Fleming, S. M., \& Haggard, P. (2010). Subliminal priming of actions influences sense of control over effects of action. Cognition, 115(1), 26-38. 